\title{
Cloning of Three Antiporter Genes from Arabidopsis and Rice for Over-Expressing Them in Farmer Popular Tomato Varieties of Bangladesh
}

\author{
Samsad Razzaque ${ }^{1,2}$, Debashis Chakraborty ${ }^{1,2}$, Rumana Sultana Tammi ${ }^{1}$, Sabrina M. Elias' , \\ Zeba I. Seraj ${ }^{1}$, Aparna Islam ${ }^{*}$ \\ ${ }^{1}$ Plant Biotechnology Lab, Department of Biochemistry and Molecular Biology, University of Dhaka, Dhaka, \\ Bangladesh \\ ${ }^{2}$ Biotechnology Program, Department of Mathematics and Natural Sciences, BRAC University, Dhaka, \\ Bangladesh \\ Email: ${ }^{*}$ aparna@bracu.ac.bd
}

Received 11 November 2014; revised 5 December 2014; accepted 15 December 2014

Copyright $(2014$ by authors and Scientific Research Publishing Inc.

This work is licensed under the Creative Commons Attribution International License (CC BY).

http://creativecommons.org/licenses/by/4.0/

(c) (i) Open Access

\begin{abstract}
Salinity is one of the most critical environmental problems, which causes plant growth retardation by disturbing intracellular ion homeostasis. The $\mathrm{Na}^{+} / \mathrm{H}^{+}$antiporter plays an important role in resistance to salt stress by sequestering $\mathrm{Na}^{+}$in exchange for $\mathrm{H}^{+}$across the vacuolar membranes. In the current study, the coding regions of two Arabidopsis antiporters (AtNHX1 and AtNHX2) and one rice antiporter (OsNHX1) were amplified by target specific PCR. PCR amplicons were first cloned into $p E N T R / D-T O P O$ and later recombined with a destination vector (pK7WG2.0) by LR reaction. Positive clones were selected by PCR, restriction digestion (RD) and sequencing. They were then transformed into Agrobacterium tumefaciens (LBA4404 strain) for subsequent transformation of farmer popular tomato varieties.
\end{abstract}

Keywords

Antiporters, pENTR/D-TOPO, pK7WG2.0, Agrobacterium

\section{Introduction}

Agricultural productivity is severely hindered by salinity, since a large terrestrial area of the world is affected by

"Corresponding author.

How to cite this paper: Razzaque, S., Chakraborty, D., Tammi, R.S., Elias, S.M., Seraj, Z.I. and Islam, A. (2014) Cloning of Three Antiporter Genes from Arabidopsis and Rice for Over-Expressing Them in Farmer Popular Tomato Varieties of Bangladesh. American Journal of Plant Sciences, 5, 3957-3963. http://dx.doi.org/10.4236/ajps.2014.526414 
salt levels harmful for plant growth [1]. Water potential homeostasis and ion distribution in plants are disturbed by high salt stress and this disturbance occurs at both the cellular and whole plant level leading to molecular damage, growth retardation and plant death [2]. Twenty percent land of Bangladesh is in the coastal area, of which $53 \%$ is affected by various degrees of salinity [3]. Moreover, increasing sea levels and upper riparian water withdrawal is resulting in salinization of more and more cultivable areas further north from the coastal areas and is one of the major threats to crop production of the country.

In addressing the problem of salt stress both conventional breeding and transgenic approaches have been attempted [4]. However, the transgenic approach is regarded more successful for the development of abiotic stress tolerant plants because it can help control timing, tissue specificity and expression level of the introduced genes [5]-[8]. A number of genes and transcription factors have already been tested for their efficiency in conferring salinity tolerance. Salt overly sensitive 1 (SOS1) gene from Arabidopsis thaliana is reported to be a plasma membrane antiporter and its over-expression has been shown to improve salt tolerance in Arabidopsis [9]. Over-expression of a vacuolar $\mathrm{Na}^{+} / \mathrm{H}^{+}$antiporter (AtNHX1) in Arabidopsis allowed transgenic plants to grow in high concentrations of salt [10]. The vital role of $\mathrm{Na}^{+}$compartmentation has been further demonstrated in transgenic tomato plants over-expressing AtNHX1. Such tomato plants grown in the presence of $200 \mathrm{mM} \mathrm{NaCl}$ were able to grow, flower and set fruit [11]. Over-expression of rice vacuolar $\mathrm{Na}^{+} / \mathrm{H}^{+}$antiporter (OsNHX1) has been found to confer salt tolerance to transgenic rice [12] [13] and maize [14]. There are several reports on the importance of vacuolar $\mathrm{Na}^{+}$compartmentation in plant salt tolerance [15]-[17]. Additional evidence supporting the role of vacuolar transport in salt tolerance has been provided by Arabidopsis plants over-expressing a vacuolar $\mathrm{H}^{+}$-PPiase [18]. These results suggest that enhanced vacuolar $\mathrm{H}^{+}$-pumping in transgenic plants allow vacuolar sodium accumulation via the vacuolar $\mathrm{Na}^{+} / \mathrm{H}^{+}$antiporter.

The Arabidopsis thaliana vacuolar $\mathrm{Na}^{+} / \mathrm{H}^{+}$antiporter AtNHX1 is a determinant of salt tolerance [9]. Sequence similarity, protein topology and conserved functional domains in AtNHX1 and mammalian $N H E ~ \mathrm{Na}^{+} / \mathrm{H}^{+}$antiporters helped identify five additional AtNHX genes (AtNHX1 to AtNHX6) [19]. Similar to AtNHX1, AtNHX2 and AtNHX5 are localized in the tonoplast of plant cells whereas the expression of the other antiporters (AtNHX3, AtNHX4 and AtNHX6) may not be associated with salt adaptation, at least at the seedling stage [20]. On the other hand, the OsNHX family was also found to be a competent determinant of salt tolerance in transgenic plants [21]. Five NHX-type antiporter genes have been found in rice (OsNHX1 through OsNHX5) and over-expression of the vacuolar OsNHX1 gene was found to improve tolerance in both rice cells and plants. OsNHX1 had the ability to suppress $\mathrm{Na}^{+}, \mathrm{Li}^{+}, \mathrm{K}^{+}$and hygromycin sensitivity of yeast $n h x 1$ mutants [12]. In the current study, coding regions of two antiporter genes (AtNHX1 and AtNHX2) from Arabidopsis and one from rice (OsNHX1) have been cloned separately with the aim to transform and over-express them in farmer popular Bangladeshi tomato varieties.

\section{Materials and Methods}

The target gene sequences were collected from NCBI database and the "gi" for the genes and their individual sequence lengths are provided in Table 1 . The coding regions were aligned by ClustalW2

(http://www.ebi.ac.uk/Tools/msa/clustalw2/) and sequence similarities were noted both at the nucleotide and amino acid level.

Arabidopsis seeds were grown for 20 - 25 days and $150 \mathrm{mM}$ salt stress was applied for 24 hrs before extracting total RNA using TRIZOL following the manufacturer's protocol (Invitrogen, USA). The extracted RNA was quantified using Nanodrop ${ }^{\circledR}$ spectrophotometer ND-1000 (Thermo Fisher Scientific Inc., USA) and the cDNA was synthesized from isolated RNA using SuperScript ${ }^{\mathrm{TM}}$ first-strand synthesis kit (Invitrogen, NY, USA).

Table 1. Three antiporter gene accessions with their sequence lengths.

\begin{tabular}{ccccc}
\hline Sl & Genes & Accession & Seq length (nucleotide) & Seq length (amino acid) \\
\hline 1. & AtNHX1 & gi|30690553_471-2087 & $1617 \mathrm{bp}$ & $538 \mathrm{bp}$ \\
2. & AtNHX2 & gi|334185089_348-1988 & $1641 \mathrm{bp}$ & $546 \mathrm{bp}$ \\
3. & OsNHX1 & gi|5731736_297-1904 & $1608 \mathrm{bp}$ & $535 \mathrm{bp}$ \\
\hline
\end{tabular}


Three primer sets were designed for the three different gene targets (Table 2). The forward primers in each case were designed with a CACC overhang to ensure compatibility with the $p E N T R / D-T O P O$ vector (Invitrogen, NY, USA). All three target genes were amplified using different PCR amplification programs. PCR optimization for AtNHX1 was as follows: initial denaturation at $95^{\circ} \mathrm{C}$ for 5 min and 35 cycles of denaturation at $95^{\circ} \mathrm{C}$ for 1 min, annealing at $61.5^{\circ} \mathrm{C}$ for $1 \mathrm{~min}$, extension at $72^{\circ} \mathrm{C}$ for $1.30 \mathrm{~min}$ followed by a final extension at $72^{\circ} \mathrm{C}$ for 10 min. The second target coding region (AtNHX2) (1.6 kbp) was amplified following the PCR condition which was optimized with initial denaturation at $95^{\circ} \mathrm{C}$ for $5 \mathrm{~min}$ and 35 cycles of denaturation at $95^{\circ} \mathrm{C}$ for $1 \mathrm{~min}$, annealing at $59.5^{\circ} \mathrm{C}$ for $1 \mathrm{~min}$, extension at $72^{\circ} \mathrm{C}$ for $1.30 \mathrm{~min}$ and final extension at $72^{\circ} \mathrm{C}$ for $10 \mathrm{~min}$. Later the coding region of $O s N H X 1$ gene was amplified from a pre-cloned $O s N H X 1$ construct [13] deleting its UTR portion. The PCR was optimized with initial denaturation at $95^{\circ} \mathrm{C}$ for $5 \mathrm{~min}$ and 35 cycles of denaturation at $95^{\circ} \mathrm{C}$ for $1 \mathrm{~min}$, annealing at $63.5^{\circ} \mathrm{C}$ for $1 \mathrm{~min}$, extension at $72^{\circ} \mathrm{C}$ for $2.10 \mathrm{~min}$ and final extension at $72^{\circ} \mathrm{C}$ for $10 \mathrm{~min}$. A final concentration of $2.3 \mathrm{mM} \mathrm{MgCl}_{2}, 0.1 \mathrm{mM}$ dNTPs and $0.3 \mu \mathrm{M}$ of each primer and 1 unit of recombinant Taq polymerase (Invitrogen, Carlsbad, CA, USA) were used for each target gene amplification.

Final PCR amplicons were gel extracted and quantified using a nanodrop. The three target genes were cloned into $p E N T R / D-T O P O$ vector (Invitrogen, NY, USA) by following the manufacturer's protocol (Invitrogen, NY, USA). The $p E N T R \_O s N H X 1, p E N T R \_A t N H X 1$ and $p E N T R \_A t N H X 2$ plasmid constructs were individually transformed into $E$. coli DH5 $\alpha$ competent cells using standard protocols [22]. Successful cloning of the genes were confirmed by gene specific PCR, restriction digestion of the isolated plasmids with SacI and EcoRV (NEB, Ipswich, MA, USA) followed by sequencing of the clones. $p E N T R / D-T O P O$ cloning allowed recombining the desired sequences of the three different genes into the destination vector ( $p$ K7WG2.0) in three separate LR recombination events [23]. The LR reactions were carried out following the manufacturer's protocol (Invitrogen, NY, USA). Positive clones were first screened by PCR using gene specific primers and then by restriction digestion with HindIII (NEB, Ipswich, MA, USA).

Finally, Agrobacterium tumefaciens (LBA4404 strain) was transformed by electroporation with $p K 7 W G 2_{-}$ OsNHX1, pK7WG2_AtNHX1 and pK7WG2_AtNHX2 constructs using standard protocols [22]. Positive clones were selected based on PCR reactions with gene specific primers (Table 2).

\section{Results and Discussion}

Sequences of all three antiporters were retrieved from NCBI GenBank and checked for their similarities at both the nucleotide and amino acid levels. The percent matrix for the nucleotide sequences revealed that AtNHX1 coding region is closely similar to AtNHX2 (83.36\%) whereas the OsNHX1 is approximately $70 \%$ similar to both AtNHX1 and AtNHX2 coding regions (Table 3). Amino acid sequence specificity has been shown to have a role in salt stress tolerance [24]. Therefore, all three genes will individually be cloned into a transformation vector for over-expression in tomato to see the efficiency of these genes in conferring salt tolerance to the transgenic lines.

Identities based on amino acid sequences of OsNHX1, AtNHX1 and AtNHX2 genes are closer than the nucleotide bases (Table 4).

Three different PCR programs were optimized for amplifying the target genes (OsNHX1, AtNHX1 and AtNHX2). PCR amplicons of the desired size were then gel purified (Figure 1(a)).

Table 2. Primer list with their corresponding sequences used in this study.

\begin{tabular}{ccc}
\hline Sl & Primer & Sequence \\
\hline 1. & OsNHX1_F & CACCATGGGGATGGAGGTGGCG \\
2. & OsNHX1_R & TCATCTTCCTCCATGGCTCTGC \\
3. & $A t N H X 1 \_F$ & CACCATGTTGGATTCTCTAGTGTC \\
4. & $A t N H X 1 \_R$ & TCAAAGCTTTTCTTCCACG \\
5. & $A t N H X 2 \_F$ & CACCGAAAGATGACAATGTTCGCCTC \\
6. & $A t N H X 2 \_R$ & TCAAGGTTTACTAAGATCATGGCTG \\
\hline
\end{tabular}


Table 3. Percent identity matrix (nucleotide bases).

\begin{tabular}{ccccccc}
\hline Sl & Genes & Accession & Seq length & Col 1 & Col 2 & Col 3 \\
\hline 1. & AtNHX1 & gi|30690553_471-2087 & 1617 & 100.00 & 83.36 & 70.87 \\
2. & AtNHX2 & gi|334185089_348-1988 & 1641 & 83.36 & 100.00 & 71.02 \\
3. & OsNHX1 & gi|5731736_297-1904 & 1608 & 70.87 & 71.02 & 100.00 \\
\hline
\end{tabular}

Table 4. Percent identity matrix (amino acid bases).

\begin{tabular}{|c|c|c|c|c|c|c|}
\hline Sl & Genes & Accession & Seq length & Col 1 & Col 2 & Col 3 \\
\hline 1. & AtNHX1 & gi|30690553_471-2087 & 538 bp & 100.00 & 88.66 & 72.93 \\
\hline 2. & AtNHX2 & gi|334185089_348-1988 & 546 bp & 88.66 & 100.00 & 74.95 \\
\hline 3. & OsNHX1 & gi|5731736_297-1904 & 535 bp & 72.93 & 74.95 & 100.00 \\
\hline
\end{tabular}

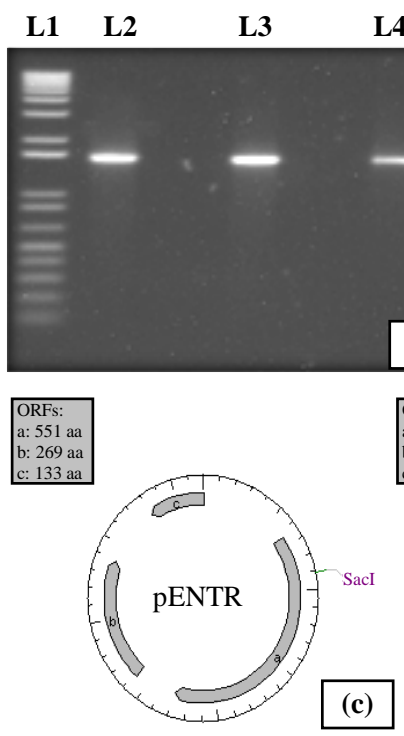

L4 L1 L2 L3 L4 L L5

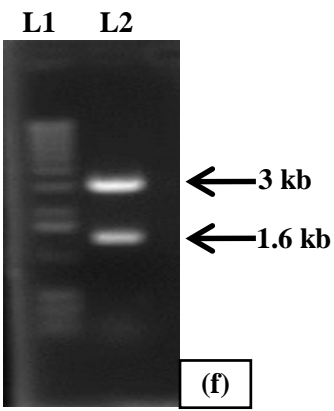

(a)
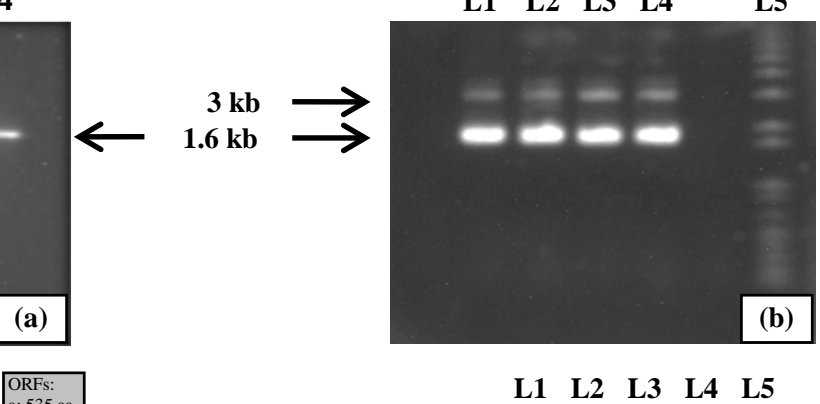

269 aa
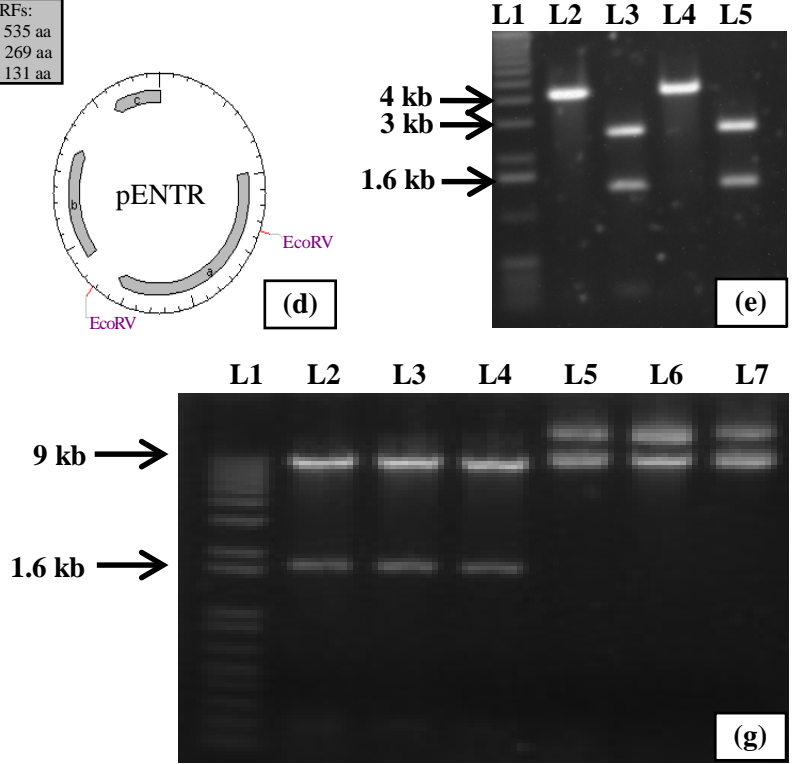

Figure 1. Molecular verification of three antiporter genes cloned individually in pENTR vectors. (a) L1: 1 Kb + DNA Ladder. L2 - L4: Amplified and gel purified coding regions of AtNHX2, AtNHX1 and OsNHX1, respectively; (b) Recombinant pENTR/D-TOPO vectors harbouring OsNHX1, AtNHX1 and AtNHX2 genes. L1: pENTR_AtNHX2. L2: pENTR_AtNHX1. L3 - L4: pENTR_OsNHX1. L5: $1 \mathrm{~Kb}+$ DNA Ladder; (c) (d) pENTR_OsNHX1, pENTR_AtNHX1 showing cutting sites for SacI and EcoRV; (e) L1: $1 \mathrm{~Kb}+$ DNA Ladder. L2 and L4: Single cut bands produced by SacI and; L3 - L5: Two fragments produced by EcoRV; (f) pENTR_AtNHX2 digested with EcoRV. L1: 1 Kb + DNA Ladder. L2: Double digested pENTR_ AtNHX2 with EcoRV; (g) Plasmids isolated after LR reaction between entry clones ( $p E N T R \_O s N H X 1, p E N T R \_A t N H X 1$ and pENTR_AtNHX2) and destination vector ( $p K 7 W G 2.0)$. The isolated plasmids were digested with Hind III. L1: 1 Kb + DNA Ladder. L2 - 4: Digested products of pK7WG2_AtNHX2. pK7WG2_AtNHX1 and pK7WG2_OsNHX1 respectively. L5 - L7: Uncut $p K 7 W G 2 \_A t N H X 2$, pK7WG2_AtNHX1 and pK7WG2_OsNHX1, respectively. 
The PCR amplified products of the three antiporter genes were cloned into the entry vector $p E N T R / D-T O P O$. The vector is designed to facilitate rapid, directional TOPO ${ }^{\circledR}$ cloning of blunt-end PCR products for entry into the Gateway ${ }^{\circledR}$ System [8]. The system was adopted for this experiment since inserts can be cloned in the vector in correct orientation with efficiencies equal to or greater than 90\% (Invitrogen, NY, USA). Following transformation and $\mathrm{O} / \mathrm{N}$ incubation, colonies were observed on the LB plates containing the antibiotic kanamycin. Isolating of the desired size plasmids confirmed successful cloning (Figure 1(b)).

The plasmids were further validated by gene specific PCR—performed according to conditions mentioned in the method section (figures not provided). PCR positive clones were then digested with restriction enzymes SacI and $E c o R V$. The predicted cutting fragment for SacI was single and double cutting fragments were predicted for EcoRV. The digested products were visualized as having the correct fragment lengths (Figures 1(c)-(f)). All three constructs ( $p E N T R \_O s N H X 1, p E N T R \_A t N H X 1 \& p E N T R \_A t N H X 2$ ) were predicted to digest at $2.8 \mathrm{kbp}$ and $1.3 \mathrm{kbp}$ for the EcoRV enzyme and for SacI at $4.1 \mathrm{kbp}$. Further confirmation of the OsNHX1, AtNHX1 and AtNHX2 cloning into $p E N T R$ were performed by sequencing using gene-specific and M13 primer pairs. The sequenced results showed $100 \%$ similarities with the sequences retrieved from the databases.

$p E N T R$ clones with the target antiporter genes (OsNHX1, AtNHX1 and AtNHX2) were recombined into binary vector $p K 7 W G 2.0$ through LR reactions. This LR recombination reaction creates an expression clone for plant transformation retaining the selectable markers for transformation into bacteria and plants [23]. The destination binary vector ( $p K 7 W G 2.0$ ) is compatible for both E. coli and Agrobacterium. Following LR recombination reactions and transformations, colonies were observed on the LB plates containing the antibiotics, spectinomycin and streptomycin. Plasmids were isolated from these colonies and positive clones were confirmed by PCR using genes specific primers (Figures not shown) and by HindIII digestion (Figure 1(g)). As predicted for HindIII all constructs (pK7WG2_OsNHX1, pK7WG2_AtNHX1 \& pK7WG2_AtNHX2) were positive for the expected DNA fragments were at $\sim 9.5 \mathrm{kbp}$ and $1.7 \mathrm{kbp}$. The positive clones showed the right size for all three constructs (Figure 1(g)).

The positive constructed destination vectors were transformed into Agrobacterium (LBA4404 strain) by electroporation. The transformed plates were kept at $28^{\circ} \mathrm{C}$ for $72 \mathrm{hrs}$ and positive colonies were screened by PCR using gene specific primers (Table 2). The PCR reactions were conducted to amplify the whole regions of OsNHX1 (1.6 kbp), AtNHX1 (1.6 kbp) and AtNHX2 gene (1.6 kbp). The genes were amplified to the expected size at $1.6 \mathrm{kbp}$ (figure not shown).

During this experiment several modifications had to be made to the manufacturer's protocol for successful cloning of the $1.6 \mathrm{kdp}$ NHX genes into $p E N T R / D-T O P O$. The incubation time had to be extended from $1 \mathrm{hr}$ to 2 hrs and the cloning reaction volume was made $10 \mu \mathrm{l}$ instead of $6 \mu \mathrm{l}$ [25]. In addition to this, the LR reaction protocol also had to be modified. The initial concentration for the LR was optimized to $25 \mathrm{ng} / \mu \mathrm{l}$. The vector to insert ratio for both pENTR and LR reaction had to be raised to 1:1. These modifications will help cloning other genes using the Gateway cloning strategy.

The final aim of the current study is to develop salt tolerant tomato varieties without disturbing their high yield quality. The transformation protocol has already been optimized [26] for the tomato varieties and the transformation processes with these constructs are underway. In future, transgenic tomatoes containing these constructs will be screened for their levels of salinity tolerance and yield potential. Moreover, effectiveness of these genes will also be compared to study the effect if any of the differences present in the three gene sequences.

\section{Acknowledgements}

The authors would like to thank Bangladesh Academy of Sciences for BAS-USDA PALS-LI03 (Tomato) grant under BAS-USDA Endowment fund program for funding the project.

\section{References}

[1] Yamaguchi, T. and Blumwald, E. (2005) Developing Salt-Tolerant Crop Plants: Challenges and Opportunities. Trends in Plant Science, 10, 615-620. http://dx.doi.org/10.1016/j.tplants.2005.10.002

[2] Zhu, J.-K. (2001) Plant Salt Tolerance. Trends in Plant Science, 6, 66-71. http://dx.doi.org/10.1016/S1360-1385(00)01838-0

[3] Haque, S. (2006) Salinity Problems and Crop Production in Coastal Regions of Bangladesh. Pakistan Journal of Bot- 
any, 38, 1359-1365.

[4] Mittler, R. and Blumwald, E. (2010) Genetic Engineering for Modern Agriculture: Challenges and Perspectives. Annual Review of Plant Biology, 61, 443-462. http://dx.doi.org/10.1146/annurev-arplant-042809-112116

[5] Arzani, A. (2008) Improving Salinity Tolerance in Crop Plants: A Biotechnological View. In Vitro Cellular \& Developmental Biology-Plant, 44, 373-383. http://dx.doi.org/10.1007/s11627-008-9157-7

[6] Bhatnagar-Mathur, P., Vadez, V. and Sharma, K.K. (2008) Transgenic Approaches for Abiotic Stress Tolerance in Plants: Retrospect and Prospects. Plant Cell Reports, 27, 411-424. http://dx.doi.org/10.1007/s00299-007-0474-9

[7] Tuteja, N., Verma, S., Sahoo, R.K., Raveendar, S. and Reddy, I.B.L. (2012) Recent Advances in Development of Marker Free Transgenic Plants: Regulation and Biosafety Concern. Journal of Bioscience, 37, 162-197. http://dx.doi.org/10.1007/s12038-012-9187-5

[8] Ashraf, M.A., Biswas, S., Razzaque, S., Haque, T. and Seraj, Z.I. (2014) Cloning and Characterization of Alcohol Dehydrogenase (Adh) Promoter Region for Expression Under Submergence and Salinity Stress. Plant Tissue Culture and Biotechnology, 24, 111-120. http://dx.doi.org/10.3329/ptcb.v24i1.19252

[9] Shi, H.Z., Lee, B.-H., Wu, S.-J. and Zhu, J.-K. (2002) Overexpression of a Plasma Membrane $\mathrm{Na}^{+} / \mathrm{H}^{+}$Antiporter Gene Improves Salt Tolerance in Arabidopsis thaliana. Nature Biotechnology, 21, 81-85. http://dx.doi.org/10.1038/nbt766

[10] Apse, M.P., Aharon, G.S., Snedden, W.A. and Blumwald, E. (1999) Salt Tolerance Conferred by Overexpression of a Vacuolar $\mathrm{Na}^{+} / \mathrm{H}^{+}$Antiport in Arabidopsis. Science, 285, 1256-1258. http://dx.doi.org/10.1126/science.285.5431.1256

[11] Zhang, H.X. and Blumwald, E. (2001) Transgenic Salt-Tolerant Tomato Plants Accumulate Salt in Foliage But Not in Fruit. Nature Biotechnology, 19, 765-768. http://dx.doi.org/10.1038/90824

[12] Fukuda, A., Nakamura, A., Tagiri, A., Tanaka, H., Miyao, A., Hirochika, H. and Tanaka, Y. (2004) Function, Intracellular Localization and the Importance in Salt Tolerance of a Vacuolar $\mathrm{Na}^{+} / \mathrm{H}^{+}$Antiporter from Rice. Plant and Cell Physiology, 45, 146-159. http://dx.doi.org/10.1093/pcp/pch014

[13] Islam, S.T. and Seraj, Z.I. (2009) Vacuolar $\mathrm{Na}^{+} / \mathrm{H}^{+}$Antiporter Expression and Salt Tolerance Conferred by Actin1D and CaMV35S Are Similar in Transgenic Binnatoa Rice. Plant Tissue Culture and Biotechnology, 19, 257-262.

[14] Chen, M., Chen, Q.J., Niu, X.G., Zhang, R., Lin, H.Q., Xu, C.Y., Wang, X.C., Wang, G.Y. and Chen, J. (2007) Expression of OsNHX1 Gene in Maize Confers Salt Tolerance and Promotes Plant Growth in the Field. Plant, Soil and Environment, 11, 490-498.

[15] Wu, C.A., Yang, G.D., Meng, Q.W. and Zheng, C.C. (2004) The Cotton GhNHX1 Gene Encoding a Novel Putative Tonoplast $\mathrm{Na}^{+} / \mathrm{H}^{+}$Antiporter Plays an Important Role in Salt Stress. Plant and Cell Physiology, 45, 600-607. http://dx.doi.org/10.1093/pcp/pch071

[16] Yin, X.Y., Yang, A.F., Zhang, K.W. and Zhang, J.R. (2004) Production and Analysis of Transgenic Maize with Improved Salt Tolerance by the Introduction of AtNHX1 Gene. Acta Botanica Sinica-English Edition, 7, 854-861.

[17] Chen, H., An, R., Tang, J.H., Cui, X.H., Hao, F.S., Chen, J. and Wang, X.C. (2007) Over-Expression of a Vacuolar $\mathrm{Na}^{+} / \mathrm{H}^{+}$Antiporter Gene Improves Salt Tolerance in an Upland Rice. Molecular Breeding, 19, 215-225. http://dx.doi.org/10.1007/s11032-006-9048-8

[18] Gaxiola, R.A., Li, J.S., Undurraga, S., Dang, L.M., Allen, G.J., Alper, S.L. and Fink, G.R. (2001) Drought- and Salt-Tolerant Plants Result from Overexpression of the AVP1 $\mathrm{H}^{+}$-Pump. Proceedings of the National Academy of Sciences of the United States of America, 98, 11444-11449. http://dx.doi.org/10.1073/pnas.191389398

[19] Yokoi, S., Quintero, F.J., Cubero, B., Ruiz, M.T., Bressan, R.A., Hasegawa, P.M. and Pardo, J.M. (2002) Differential Expression and Function of Arabidopsis thaliana NHX Na $/ \mathrm{H}^{+}$Antiporters in the Salt Stress Response. The Plant Journal, 30, 529-539. http://dx.doi.org/10.1046/j.1365-313X.2002.01309.x

[20] Panahi, B., Shahriari Ahmadi, F., Zare Mehrjerdi, M. and Moshtaghi, N. (2013) Molecular Cloning and the Expression of the $\mathrm{Na}^{+} / \mathrm{H}^{+}$Antiporter in the Monocot Halophyte Leptochloa fusca (L.) Kunth. NJAS-Wageningen Journal of Life Sciences, 64-65, 87-93. http://dx.doi.org/10.1016/j.njas.2013.05.002

[21] Fukuda, A., Nakamura, A., Hara, N., Toki, S. and Tanaka, Y. (2011) Molecular and Functional Analyses of Rice NHX-Type $\mathrm{Na}^{+} / \mathrm{H}^{+}$Antiporter Genes. Planta, 233, 175-188. http://dx.doi.org/10.1007/s00425-010-1289-4

[22] Maniatis, T., Fritsch, E.F. and Sambrook, J. (1982) Molecular Cloning: A Laboratory Manual. Vol. 545, Cold Spring Harbor Laboratory Cold Spring Harbor, New York.

[23] Karimi, M., Inzé, D. and Depicker, A. (2002) GATEWAYтм Vectors for Agrobacterium-Mediated Plant Transformation. Trends in Plant Science, 7, 193-195. http://dx.doi.org/10.1016/S1360-1385(02)02251-3

[24] Razzaque, S., Mahdi, R. and Islam, A. (2014) Identification of Synchronized Role of Transcription Factors, Genes, and Enzymes in Arabidopsis thaliana under Four Abiotic Stress Responsive Pathways. Computational Biology Journal, 2014, Article ID: 896513. http://dx.doi.org/10.1155/2014/896513 
[25] Razzaque, S., Elias, S.M., Biswas, S., Haque, T. and Seraj, Z.I. (2013) Cloning of the Plasma Membrane Sodium/Hydrogen Antiporter SOS1 for Its over Expression in Rice. Plant Tissue Culture and Biotechnology, 23, 263-273. http://dx.doi.org/10.3329/ptcb.v23i2.17527

[26] Islam, A., Chowdhury, J. and Seraj, Z.I. (2010) Establishment of Optimal Conditions for an Agrobacterium-Mediated Transformation in Four Tomato (Lycopersicon esculentum Mill.) Varieties Grown in Bangladesh. Journal of Bangladesh Academy of Sciences, 34, 171-179. http://dx.doi.org/10.3329/jbas.v34i2.6863 
Scientific Research Publishing (SCIRP) is one of the largest Open Access journal publishers. It is currently publishing more than 200 open access, online, peer-reviewed journals covering a wide range of academic disciplines. SCIRP serves the worldwide academic communities and contributes to the progress and application of science with its publication.

Other selected journals from SCIRP are listed as below. Submit your manuscript to us via either submit@scirp.org or Online Submission Portal.
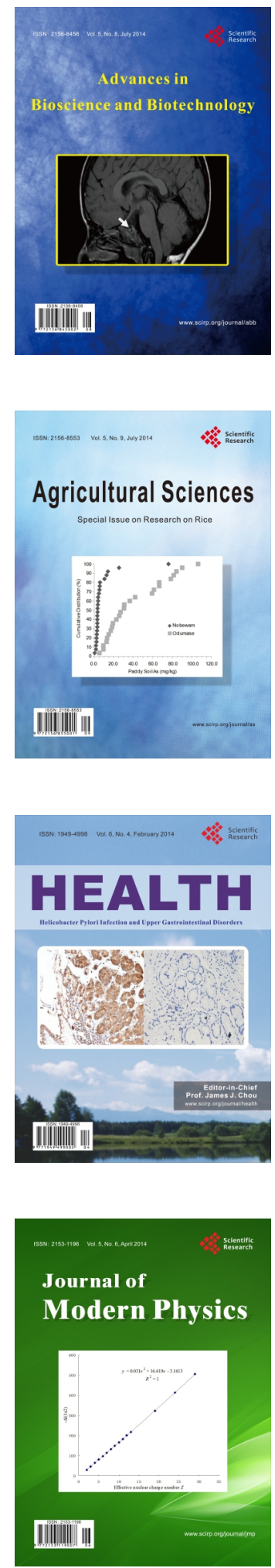
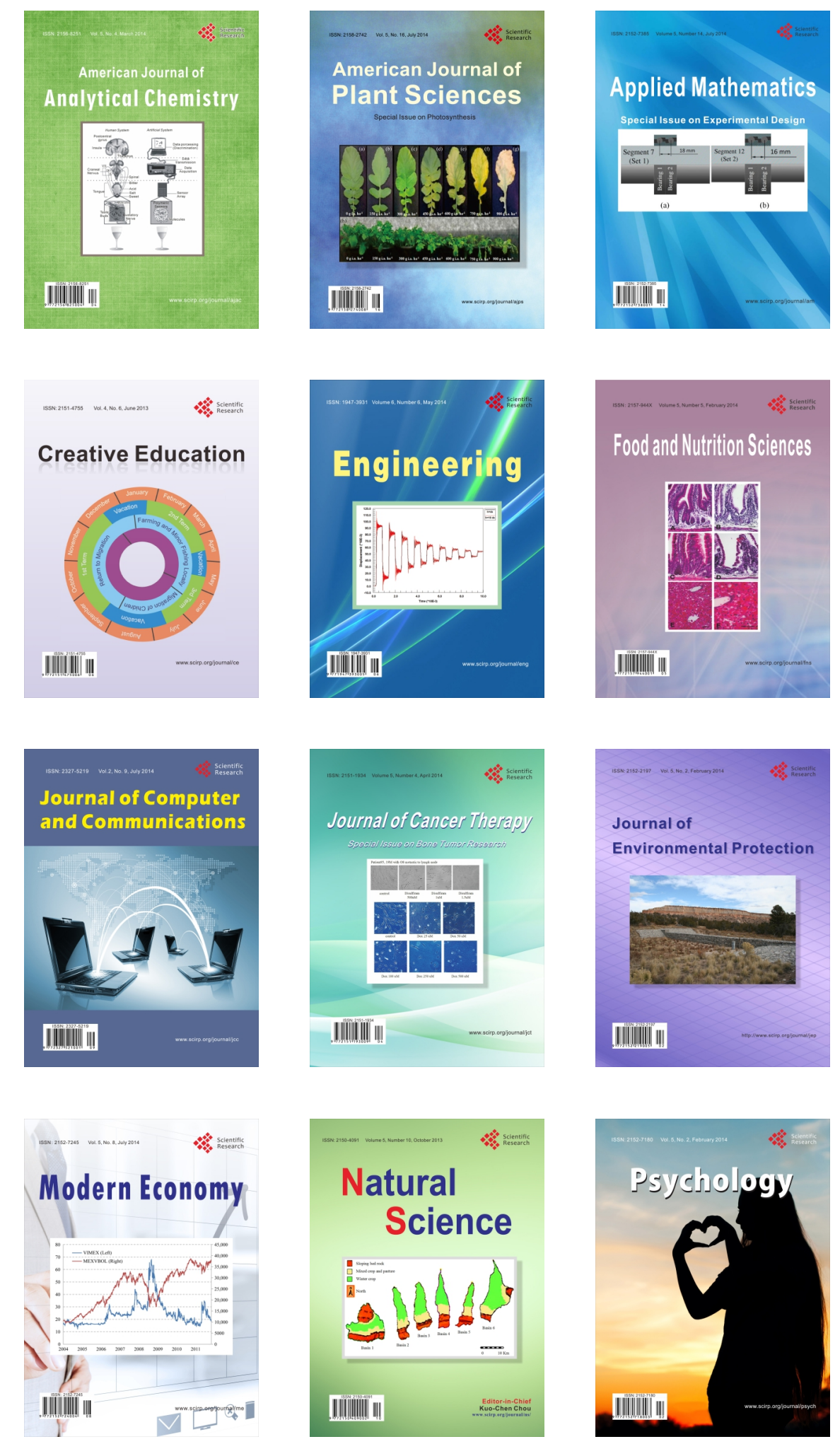